\title{
Wrong molar hemoglobin reference values-a longstanding error that should be corrected
}

\author{
Peter Lodemann • Georg Schorer • Beat M. Frey
}

Received: 17 June 2009/Accepted: 1 July 2009/Published online: 17 July 2009

(C) Springer-Verlag 2009

\section{Dear Editor,}

The molar weight of hemoglobin is $64 \mathrm{kDa}$, so $1 \mathrm{~mol}$ of hemoglobin has a weight of $64,000 \mathrm{~g}$, and $1 \mathrm{mmol}$ has a weight of $64 \mathrm{~g}$. According to this, the widely stated (e.g., in [1]) normal range of $\sim 7-12 \mathrm{mmol} / \mathrm{l}$ expressed in grams per liter would be $7 \times 64-12 \times 64 \mathrm{~g} / \mathrm{l}=448-768 \mathrm{~g} / \mathrm{l}=\sim 45-77 \mathrm{~g} / \mathrm{dl}$, and that is in clear conflict with the reference range given in the literature $(12-18 \mathrm{~g} / \mathrm{dl},[2,3])$; moreover, the calculated values are obviously $\sim 4$-fold times higher. The often-stated molar concentration of hemoglobin in SI units with a range of $7-12 \mathrm{mmol} / \mathrm{l}$ therefore is not right for the molar concentration of the whole hemoglobin molecule, but it is correct for the molar concentration of hemoglobin subunits, given the fact that one hemoglobin molecule is built of four subunits. Moreover, it reflects the molar concentration of the hem groups as well as the molar concentration of iron bound to hemoglobin. The wrong molar concentration reference values in the literature may arise from the method by which the concentration is measured: automatic analyzer measure absorption of (chemically modified) hem groups and also make the final calculation with chemical properties (e.g., absorption coefficients) of the hem groups, leading to the wrong 4-fold higher molar concentration range [3]. The molar hemoglobin concentration given in SI units therefore has to be in a range between about 2 and $3 \mathrm{mmol} / \mathrm{l}$.

Acknowledgement We would like to thank Prof. Dr. Willem H. Koppenol, Bioinorganic and Solution Chemistry Group of ETH Zuerich, for the helpful discussions.

\section{References}

1. Donald S. Young (1987): Implementation of SI units for clinical laboratory data style: specifications and conversion tables. Annals of Internal Medicine Vol. 106; No. 1

2. Beutler Ernest, Waalen Jill (2006): The definition of anemia: what is the lower limit of the normal blood hemoglobin concentration? Blood 107:1747-1750

3. Zwart A, van Assendelft OW, Bull BS, England JM, Lewis SM, Zijlstra WG (1996): Recommendations for the reference method for haemoglobinometry in human blood (ICSH standard 1995) and specifications for international haemiglobinocyanide standard (4th edition). J Clin Pathol 49(4):271-4 